\title{
EFFECT OF ENDOPHYTE INOCULATION ON THE ACCUMULATION OF MINERAL ELEMENTS AND ORGANIC ACIDS IN RICE (ORYZA SATIVA L.) UNDER OSMOTIC STRESS
}

\author{
LI, X. M. ${ }^{*}-$ LI, Y. Y. - MA, L. J. - WANG, L. L. \\ College of Life Science, Shenyang Normal University, No. 253 Huanghe North Street, \\ Shenyang, Liaoning 110034, China \\ "Corresponding authors \\ e-mail:lxmls132@163.com,wangqi5387402006@163.com
}

(Received $27^{\text {th }}$ Oct 2020; accepted $21^{\text {st }}$ Dec 2020)

\begin{abstract}
This study was conducted to investigate the effects of endophyte inoculation on the growth, mineral element and organic acid content of non-endophyte inoculated seedlings (E-) and endophyte inoculated seedlings (E+) of rice (Oryza sativa $\mathrm{L}$.) under 0, 5, 10, 15 and 20\% PEG for 7 days. Osmotic stress significantly decreased plant height, shoot dry weight and chlorophyll content of the E- and E+, but root length and dry weight were first increased and then decreased. Endophyte inoculation significantly increased plant height, shoot dry weight and chlorophyll content, but decreased root length and had no effects on root dry weight. Endophyte inoculation significantly increased the $\mathrm{K}, \mathrm{Ca}, \mathrm{Mg}$, and $\mathrm{P}$ contents, but reduced the $\mathrm{Ni}$ content of the leaves and roots under osmotic stress, while it increased the Mn content of the leaves and the $\mathrm{Na}$ content of the roots. Under osmotic stress the E+ accumulated more fumarate in the leaves in comparison with the E-, as well as more malate, acetate, fumarate and oxalate in the roots. These results suggest that endophyte inoculation improved osmotic stress tolerance of rice seedlings by enhancing mineral uptake and organic acid accumulation. The application of endophytes has a beneficial effect on plant tolerance to osmotic stress.
\end{abstract}

Keywords: plant-endophyte interaction, essential element, organic acid, tolerance

\section{Introduction}

Osmotic stresses include drought and salinity. Drought is the primary factor limiting global agricultural production (Sheshbahreh et al., 2019). Drought stress affects many physiological processes, including photosynthesis, assimilate transmission, cell expansion and mineral nutrient accumulation and transfer (Devnarain et al., 2016).

Essential elements have clear physiological roles, and plants cannot complete their life cycles without them. Generally, drought inhibits the uptake and transport of most mineral ions, resulting in nutrient deficiency (Salehi et al., 2016). Maintaining the uptake and homeostasis of mineral nutrients can enhance the resistance of plants to drought stress (Waraich et al., 2011). Water deficit conditions significantly diminish the $\mathrm{P}$ and $\mathrm{K}$ content of the shoots of Matricaria chamomilla (Salehi et al., 2016). In stressed apple plants, uptake of $\mathrm{N}, \mathrm{P}, \mathrm{K}, \mathrm{Ca}, \mathrm{Mg}, \mathrm{Fe}, \mathrm{Mn}, \mathrm{Cu}, \mathrm{Zn}$, and $\mathrm{B}$ was decreased in comparison with that of well-watered plants (Liang et al., 2018).

In general, metal stress significantly increases the organic acid (OA) contents of various plant organs (Mahdavian et al., 2016), but the effects of drought stress on OAs vary. In response to water stress, the abundance of the majority of OAs decreased in wheat (Bowne et al., 2012), maize (Sicher and Barnaby, 2012) and creeping bentgrass (Jespersen et al., 2017). However, Timpa et al. (1986) reported that water-stressed cotton plants showed greater total amounts of organic acids (malate, citrate and oxalate) in comparison with irrigated plants. Under drought stress, citrate, fumarate and malate 
accumulation was enhanced in the leaves of drought-tolerant wheat plants, but decreased in the roots (Kang et al., 2019). Moreover, drought stress increased the citrate content of potato leaflets (Barnaby et al., 2015) as well as the succinate content of maize leaves in a greenhouse study (Witt et al., 2012) and the malate content of thyme leaves (Ashrafi et al., 2018). Kim et al. (2017) found that acetate content is positively correlated with the survivability of crop plants such as wheat, rice, maize and canola. Moreover, OAs are intermediates involved in the assimilation of carbon and nitrogen, as well as osmotic regulation (Ashrafi et al., 2018).

The interaction between plants and endophytes is helpful for plants to deal with stress environment (Jung et al., 2012; Chinnaswamy et al., 2018). Plant growth promoting bacteria can improve the seed germination and enhance seedling growth of tomato under osmotic stress (Bhatt et al., 2015). Plant growth promoting rhizobacteria (PGPR) can alter the ion content of the leaves of tomato plants under salt stress (Van Oosten et al., 2018). Plant OAs such as oxalate and butyrate are by various stress (Ashraf and Harris, 2004). Endophytic fungus Piriformospora indica increased the amounts of malate, citrate and oxalate in the rhizosphere soil of Brassica napus seedlings (Wu et al., 2018). Soil, foliar, and soil + foliar applications of PGPR to promote strawberry yield also increased OA content under field conditions (Kitir et al., 2019).

Rice is very sensitive to osmotic stress at different growth stages (Swapna and Shylaraj, 2017; Nahar et al., 2018). In a previous study, we found that endophyte inoculation improves rice growth by enhancing the uptake of nutrient and altering the accumulation of OA under $\mathrm{Na}_{2} \mathrm{CO}_{3}$ or $\mathrm{Pb}$ stress (Li et al., 2017, 2019). There is little information on the use of endophytes to improve the accumulation of OAs and uptake of minerals in plants under osmotic stress. Therefore, this study was to investigate the potential beneficial effects of endophyte application on rice seedling under osmotic stress.

\section{Materials and methods}

\section{Endophytic fungus and plant material}

Endophytic strain EF0801 was isolated from the leaves of Suaeda salsa grown under saline zones across China and screened for $\mathrm{Na}_{2} \mathrm{CO}_{3}$ tolerance. Molecular identification of fungus EF0801 was based on internal transcribed spacer regions, which showed that it congeneric to Sordariomycetes sp. (99\% similarity). EF0801 was cultured on potato dextrose agar (PDA) plates at $4^{\circ} \mathrm{C}$. To produce a $5 \%$ fungus culture, plates containing $75 \mathrm{~mL}$ of PDA solution were inoculated at the 3-day instar stage and cultured for 12 days at $24 \pm 1{ }^{\circ} \mathrm{C}$ with shaking at $180 \mathrm{rpm}$. The resulting fungal cultures were used for the infection treatments. The experimental materials, rice (Oryza sativa L.) seeds (Liaoxing1') were provided by Shenyang Agriculture University, China. Seeds were sterilized with $\mathrm{NaOCl}$ for $10 \mathrm{~min}$, rinsed, germinated and grown on Hoagland's solution in an illumination chamber.

\section{Experimental treatments}

Three-day-old rice seedlings were divided into: non endophyte inoculated seedlings (E-) and endophyte inoculated seedlings (E+). E- were grown on Hoagland's solution, whereas E+ were grown on Hoagland's solution containing 5\% fermentation broth, and endophyte EF0801 colonization was achieved via the rice roots. Each group (100 seedlings/pot) was exposed to 0 (control), 5, 10, 15 or 20\% PEG-6000 (w/v in Hoagland 
solution). Endophyte inoculation and PEG exposure were carried out simultaneously. According the method of Liu and Chen (2007) to determine the degree of endophyte inoculation. Roots were cleared in $20 \% \mathrm{KOH}$, acidified by $5 \%$ acetic acid and then stained. More than $90 \%$ of the E+ were colonized, whereas the E- were not colonized. The rice seedlings were cultured in an illumination chamber $\left(28^{\circ} \mathrm{C} / 22^{\circ} \mathrm{C}\right.$ day/night, $14 / 10 \mathrm{~h}$ light/dark, $800 \mu \mathrm{mol} \mathrm{m} \mathrm{m}^{-2} \mathrm{~s}^{-1} \mathrm{PPFD}$, and $80 \%$ air humidity). Fresh Hoagland's solution was added every day. After one week, the seedlings were collected and prepared for the analyses.

\section{Estimation of growth parameters}

Shoot height and root length of ten seedlings were recorded and then they were ovendried at $80^{\circ} \mathrm{C}$ for $48 \mathrm{~h}$, after which the dry weight was measured.

\section{Estimation of chlorophyll (Chl) content}

Chlorophyll were extracted from fresh leaf with $80 \%$ acetone in the dark. Chl content was measured using the method reported by Lichtenthaler (1987).

\section{Estimation of mineral elements}

The leaves and roots of seedlings were oven-dried, ground and then pass through a 100 -mesh sieve. Each sample $(100 \mathrm{mg})$ was digested with $\mathrm{HNO}_{3} / \mathrm{HClO}_{4}(5: 1[\mathrm{v} / \mathrm{v}])$ at $2600 \mathrm{kPa}$ for $30 \mathrm{~min}$ in a microwave oven and brought to $50 \mathrm{~mL}$ with ultrapure water. The contents of macroelements (K, Ca, Mg and P) and microelements (Fe, Zn, Mn and $\mathrm{Ni}$ ) were estimated using an inductively coupled plasma atomic emission spectrometer (ICP model Liberty 200, Varian Australia Pty. Ltd., Mulgrave Victoria, Australia) as reported by Filek et al. (2012).

The percentage changes in measured elemental content per seedling

$(\%)=[($ measured elemental content in $\mathrm{E}+)$ - (measured elemental content in E-) $] /($ measured elemental content in E- $) \times 100$

\section{Estimation of OAs}

Fresh sample was ground in deionized water, incubated at $70{ }^{\circ} \mathrm{C}$ for $15 \mathrm{~min}$, and centrifuged at $10,000 \times g$ at $4{ }^{\circ} \mathrm{C}$ for $15 \mathrm{~min}$. The supernatant was filtered, evaporated to dryness under reduced pressure at $40{ }^{\circ} \mathrm{C}$, and then dissolved in ultrapure water to allow estimation of OAs by high performance liquid chromatography (Agilent 1200 HPLC System) according to the methods reported by Li et al. (2017).

\section{Data analysis}

The normality and homoscedasticity of the data were tested prior to statistical analysis. The effects of endophyte and osmotic stress were analyzed using two-way ANOVA. The threshold of significance for differences among the treatments was used LSD multiple comparisons $(p<0.05)$. 


\section{Results}

\section{Growth parameter and chlorophyll (Chl) content}

Osmotic stress significantly decreased the plant height and Chl content of the E- and E+ (Fig. 1), but first increased and then decreased root length (Table 1). Endophyte inoculation significantly increased plant height and Chl content, but significantly decreased root length under osmotic stress.

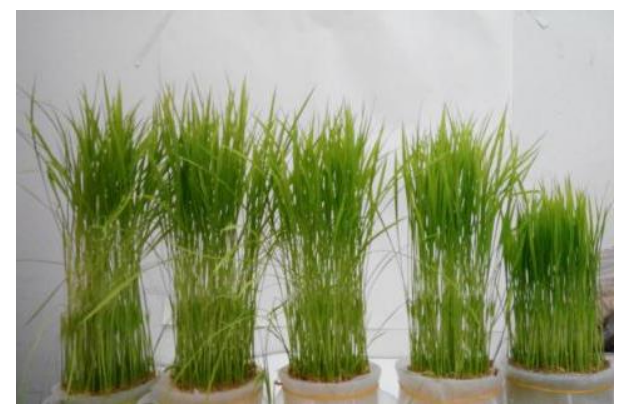

$\begin{array}{lcccc}0 & 5 & 10 & 15 & 20 \\ \text { Concentration of PEG (\%) }\end{array}$

E-

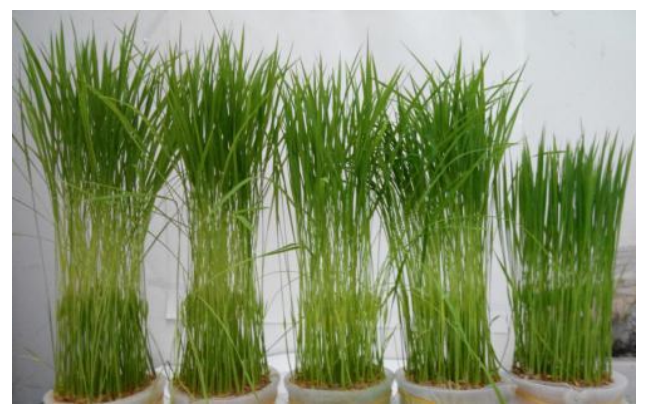

$\begin{array}{lcccc}0 & 5 & 10 & 15 & 20 \\ \text { Concentration of PEG }(\%)\end{array}$

$\mathrm{E}+$

Figure 1. Effects of endophyte inoculation on the growth of rice seedlings subjected to osmotic stress

Table 1. Effects of endophye inoculation on the growth, dry weight and Chl content of rice seedlings subjected to osmotic stress

\begin{tabular}{c|c|c|c|c|c}
\hline Treatments & $\begin{array}{c}\text { Plant height } \\
(\mathbf{c m})\end{array}$ & $\begin{array}{c}\text { Root length } \\
(\mathbf{c m})\end{array}$ & $\begin{array}{c}\text { Dry weight of } \\
\text { shoots } \\
\text { (mg/10 plant) }\end{array}$ & $\begin{array}{c}\text { Dry weight of } \\
\text { roots } \\
(\mathbf{m g} / \mathbf{1 0} \text { plant })\end{array}$ & $\begin{array}{c}\text { Chla+b content } \\
(\mathbf{m g} / \mathbf{g} \cdot \mathbf{F W})\end{array}$ \\
\hline $\mathrm{E}-$ & & & & & \\
0 & $18.89 \pm 0.71 \mathrm{~cd}$ & $9.12 \pm 0.58 \mathrm{~b}$ & $70.68 \pm 4.29 \mathrm{a}$ & $22.18 \pm 0.39 \mathrm{bc}$ & $2.60 \pm 0.06 \mathrm{c}$ \\
5 & $17.75 \pm 0.95 \mathrm{e}$ & $9.67 \pm 0.46 \mathrm{a}$ & $54.76 \pm 3.09 \mathrm{~cd}$ & $24.77 \pm 0.36 \mathrm{a}$ & $2.44 \pm 0.18 \mathrm{~cd}$ \\
10 & $16.59 \pm 0.87 \mathrm{f}$ & $7.94 \pm 0.56 \mathrm{c}$ & $49.15 \pm 2.33 \mathrm{de}$ & $22.31 \pm 0.23 \mathrm{bc}$ & $2.30 \pm 0.15 \mathrm{~cd}$ \\
15 & $14.94 \pm 0.90 \mathrm{~g}$ & $7.40 \pm 0.72 \mathrm{~cd}$ & $44.50 \pm 2.75 \mathrm{ef}$ & $21.98 \pm 0.69 \mathrm{c}$ & $2.13 \pm 0.18 \mathrm{de}$ \\
20 & $12.43 \pm 0.69 \mathrm{i}$ & $6.90 \pm 0.73 \mathrm{ed}$ & $39.37 \pm 2.67 \mathrm{f}$ & $21.74 \pm 1.11 \mathrm{c}$ & $1.82 \pm 0.13 \mathrm{e}$ \\
$\mathrm{E}+$ & & & & & \\
0 & $22.99 \pm 0.84 \mathrm{a}$ & $8.03 \pm 0.73 \mathrm{c}$ & $72.47 \pm 4.92 \mathrm{a}$ & $22.34 \pm 0.65 \mathrm{bc}$ & $3.74 \pm 0.22 \mathrm{a}$ \\
5 & $21.25 \pm 1.17 \mathrm{~b}$ & $8.80 \pm 0.66 \mathrm{~b}$ & $63.40 \pm 4.86 \mathrm{~b}$ & $25.09 \pm 0.66 \mathrm{a}$ & $3.52 \pm 0.34 \mathrm{ab}$ \\
10 & $19.38 \pm 0.78 \mathrm{c}$ & $7.22 \pm 0.41 \mathrm{de}$ & $57.12 \pm 3.02 \mathrm{bc}$ & $23.10 \pm 0.35 \mathrm{~b}$ & $3.36 \pm 0.26 \mathrm{~b}$ \\
15 & $18.29 \pm 1.04 \mathrm{de}$ & $7.06 \pm 0.86 \mathrm{de}$ & $53.12 \pm 3.82 \mathrm{~cd}$ & $22.06 \pm 0.49 \mathrm{c}$ & $2.58 \pm 0.18 \mathrm{c}$ \\
20 & $13.70 \pm 1.01 \mathrm{~h}$ & $6.36 \pm 0.56 \mathrm{f}$ & $43.12 \pm 4.06 \mathrm{ef}$ & $21.87 \pm 0.21 \mathrm{c}$ & $2.23 \pm 0.20 \mathrm{~d}$ \\
\hline
\end{tabular}

Values are the mean \pm standard deviation of three replicates. Different letters indicate a significant difference at $\mathrm{P}<0.05$ (LSD test)

Osmotic stress significantly decreased the shoot dry weight of the E- and E+, but first increased and then decreased the root dry weight (Table 1). Endophyte inoculation significantly increased the shoot dry weight under 5-15\% PEG, but showed no effects on the root dry weight. 
Osmotic stress significantly decreased the shoot dry weight of the E- and E+, but first increased and then decreased the root dry weight (Table 1). Endophyte inoculation significantly increased the shoot dry weight under 5-15\% PEG, but showed no effects on the root dry weight.

\section{The elemental content of leaves}

Osmotic stress significantly decreased the $\mathrm{K}$ and Fe contents of the E- (Fig. 2A,D). Endophyte inculation significantly increased the $\mathrm{K}$ content of the leaves of plants subjected to $20 \%$ PEG, but it had no influence on Fe content.
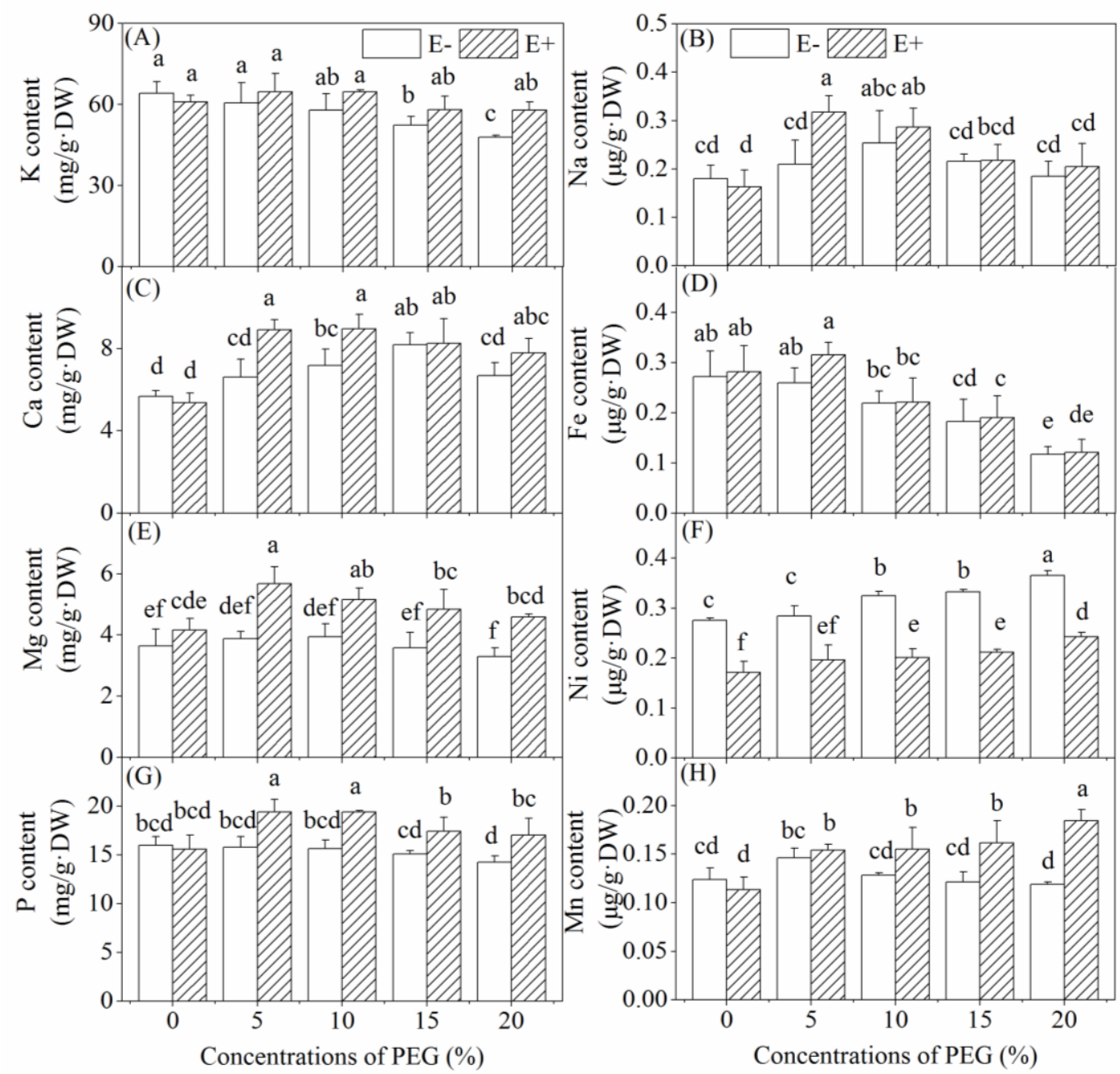

Figure 2. Effects of endophyte inoculation on the contents of macroelements ( $\mathrm{K}, \mathrm{Ca}, \mathrm{Mg}$ and $\mathrm{P})$ and microelements ( $\mathrm{Na}, \mathrm{Fe}, \mathrm{Ni}$ and $\mathrm{Mn}$ ) in the leaves of rice seedlings subjected to osmotic stress. The bars indicate the standard deviation $(n=3)$. Different letters indicate a significant difference at $P<0.05$ (LSD test)

Osmotic stress had no influence on the $\mathrm{Na}, \mathrm{Mg}, \mathrm{P}$, or $\mathrm{Mn}$ contents in the leaves of the E- (Fig. 2B,E,G,H). In the E+ seedlings, osmotic stress increased Mn content, while it first increased and then decreased the $\mathrm{Na}, \mathrm{Mg}$ and $\mathrm{P}$ contents. Endophyte inculation significantly increased the $\mathrm{Mg}, \mathrm{P}$ and $\mathrm{Mn}$ contents in plants subjected to osmotic stress 
(except Mn in plants subjected to 5\% PEG), while it only increased the Na content in plants subjected to 5\% PEG.

Osmotic stress first increased and then decreased $\mathrm{Ca}$ content, while it increased $\mathrm{Ni}$ content in the leaves of E- and E+ (Fig. 2C,F). Endophyte inoculation significantly increased the Ca content of plants subjected to 5\% and 10\% PEG, but it significantly decreased Ni content under osmotic stress.

\section{The elemental content of roots}

Osmotic stress had no influence on the $\mathrm{K}$ and $\mathrm{Fe}$ contents in the roots of the $\mathrm{E}$ (Fig. 3A,D). Endophyte inculation significantly increased the K content under 10-20\% PEG, but increased the Fe content under no PEG.
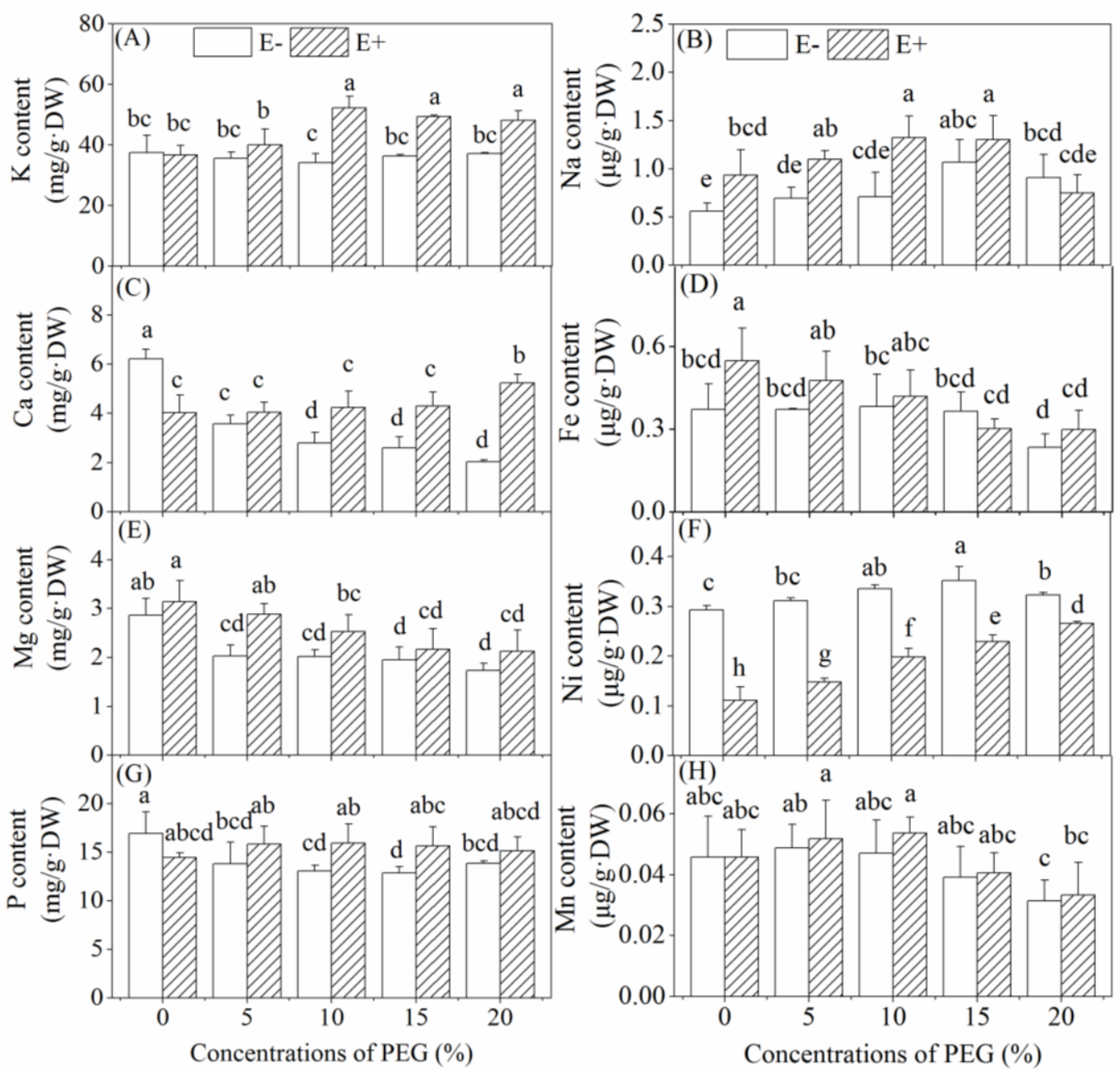

Figure 3. Effects of endophyte inoculation on the contents of macroelements ( $K, \mathrm{Ca}, \mathrm{Mg}$ and $\mathrm{P})$ and microelements ( $\mathrm{Na}, \mathrm{Fe}, \mathrm{Ni}$ and $\mathrm{Mn}$ ) in the roots of rice seedlings subjected to osmotic stress. The bars indicate the standard deviation $(n=3)$. Different letters indicate a significant difference at $P<0.05$ (LSD test)

Osmotic stress first increased and then decreased the $\mathrm{Na}$ and $\mathrm{Ni}$ contents in the roots of the E- $(F i g .3 B, F)$. Endophyte inculation significantly increased the Na content of 
plants subjected to $0-10 \%$ PEG, but it significantly decreased Ni content under osmotic stress.

Osmotic stress significantly decreased the $\mathrm{Ca}, \mathrm{Mg}, \mathrm{P}, \mathrm{Mn}$ contents in the roots of the E- (Fig. 3C,E, G,H). Endophyte inculation significantly decreased the Ca content of plants under no PEG, but it significantly increased that of plants subjected to 10-20\% PEG. Endophyte inculation significantly increased the P content of plants subjected to $10 \%$ and $15 \%$ PEG, while it had no influence on the Mg or Mn contents of plants subjected to PEG, with the exception of increased $\mathrm{Mg}$ content in plants subjected to 5\% PEG.

\section{The percentage changes of elemental content}

For the percentage changes in the measured elemental content of the E+ relative to the E-, positive values show an increase, whereas negative values show a decrease according to Eq.1 (Table 2). Under osmotic stress, the percentage changes of most measured elements were positive values, which showed that the endophyte enhanced the total elemental content per seedling. However, the percentage change of $\mathrm{Ni}$ content was negative, which showed that the endophyte reduced the total $\mathrm{Ni}$ content per seedling.

Table 2. Effects of endophye inoculation on the percentage changes in element contents per seedling subjected to osmotic stress

\begin{tabular}{c|c|c|c|c|c|c|c|c}
\hline $\begin{array}{c}\text { PEG } \\
(\%)\end{array}$ & $\mathbf{K}$ & $\mathbf{C a}$ & $\mathbf{M g}$ & $\mathbf{P}$ & $\mathbf{N a}$ & $\mathbf{F e}$ & $\mathbf{N i}$ & $\mathbf{M n}$ \\
\hline 0 & $-2.28 \pm 0.51$ & $-11.21 \pm 2.18$ & $15.53 \pm 1.24$ & $-3.64 \pm 0.61$ & $29.98 \pm 3.47$ & $18.92 \pm 3.14$ & $-42.57 \pm 5.38$ & $-5.33 \pm 1.13$ \\
5 & $21.62 \pm 6.14$ & $48.08 \pm 4.44$ & $64.73 \pm 7.15$ & $34.78 \pm 2.63$ & $66.42 \pm 5.89$ & $36.33 \pm 4.55$ & $-30.47 \pm 5.61$ & $20.37 \pm 1.87$ \\
10 & $35.80 \pm 2.55$ & $47.14 \pm 5.10$ & $47.92 \pm 3.58$ & $39.32 \pm 2.12$ & $65.49 \pm 6.47$ & $15.70 \pm 1.89$ & $-31.61 \pm 3.16$ & $37.42 \pm 3.61$ \\
15 & $33.28 \pm 3.74$ & $26.60 \pm 1.74$ & $51.11 \pm 6.02$ & $32.99 \pm 3.41$ & $21.83 \pm 2.28$ & $3.69 \pm 1.37$ & $-27.57 \pm 2.28$ & $51.41 \pm 5.17$ \\
20 & $31.81 \pm 3.65$ & $46.68 \pm 6.01$ & $45.80 \pm 5.14$ & $23.68 \pm 3.11$ & $-6.92 \pm 3.16$ & $20.87 \pm 4.47$ & $-23.92 \pm 4.25$ & $61.74 \pm 6.25$ \\
\hline
\end{tabular}

\section{The OA content of leaves}

Osmotic stress significantly decreased the tartrate, citrate and fumarate contents (Fig. 4A,E,G). Endophyte inoculation showed no significant effects on the tartrate or citrate contents of the leaves in plants under osmotic stress, with the exception of the tartrate content in plants under 20\% PEG and the citrate content in plants under no PEG. However, endophyte inoculation significantly increased the fumarate content of the leaves in the E+ under osmotic stress.

In contrast, osmotic stress significantly increased the acetate and lactate contents of the E- (Fig. 4C,D). The lactate content of the E- and E+ did not differ significantly except in those subjected to $20 \%$ PEG, while the acetate content of the E+ was significantly greater than that of the E- subjected to 0 and $20 \%$ PEG.

Osmotic stress first increased and then decreased the malate and succinate contents of the E- $(F i g .4 B, F)$. The malate content of the E+ was significantly greater than that of Esubjected to no PEG, and the succinate content of the E+ was significantly greater than that of E- subjected to 0 and $10 \%$ PEG.

Osmotic stress and endophyte inoculation had no significant effects on the oxalate content in leaves (Fig. 4H). 

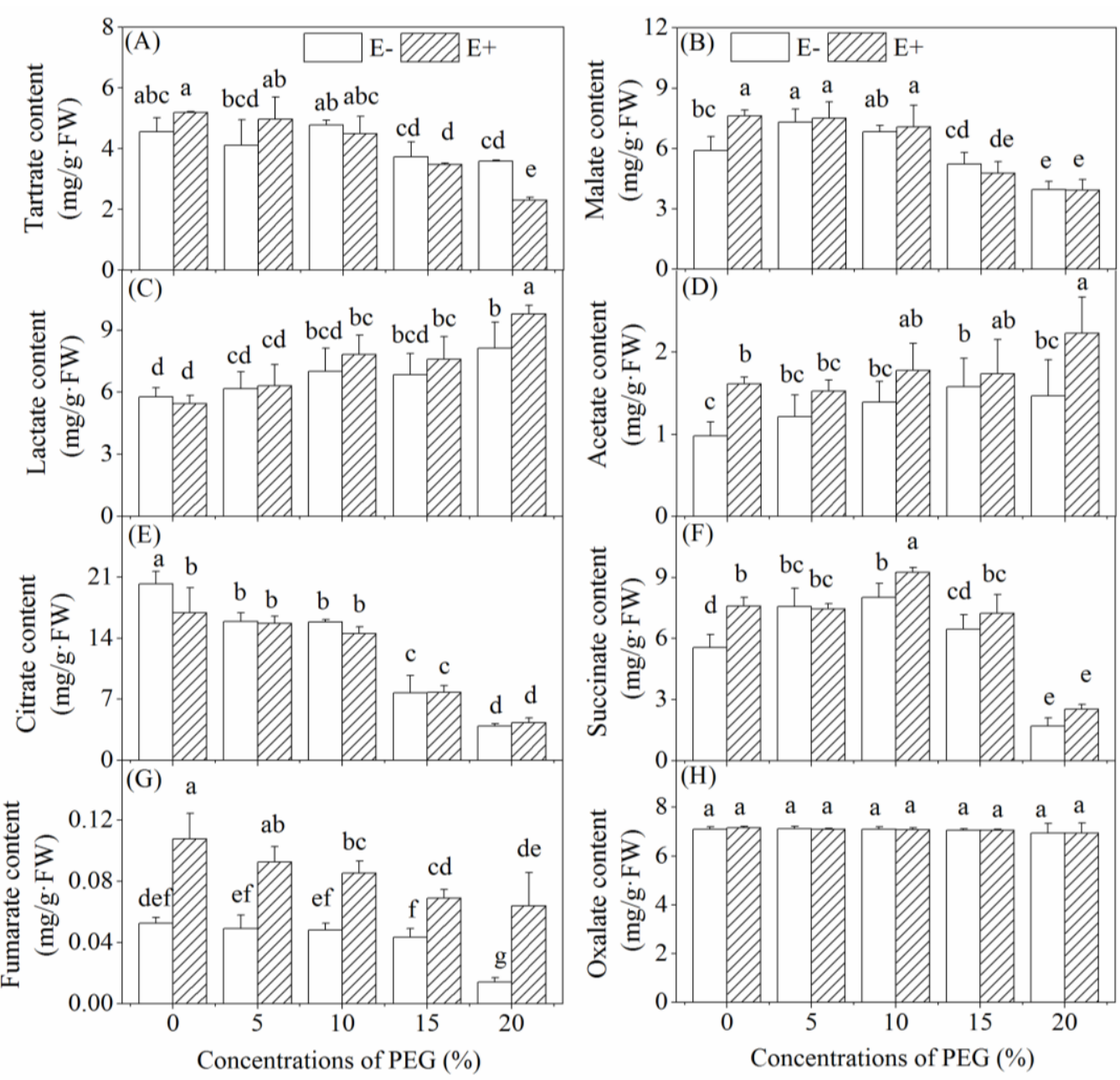

Figure 4. Effects of endophyte inoculation on the accumulation of eight OAs in the leaves of rice seedlings subjected to osmotic stress. The bars indicate the standard deviation $(n=3)$.

Different letters indicate a significant difference at $P<0.05$ (LSD test)

\section{The $O A$ content of roots}

Osmotic stress significantly decreased the tartrate, malate, citrate and oxalate contents of the E- (Fig. 5A, B,E,H). Compared to the E-, the tartrate content in the roots of the E+ subjected to $5 \%$ PEG was significantly reduced, but it was significantly increased in those subjected to $20 \%$ PEG. The malate content of the E+ was significantly greater than that of the E- subjected to $10 \%$ and $20 \%$ PEG, while the oxalate content of the E+ was significantly greater than that of the E- seedlings subjected to $15 \%$ and $20 \%$ PEG. Endophyte inoculation had no significant effect on the citrate content in roots.

Osmotic stress significantly increased the lactate and succinate contents of the E(Fig. 5C,F), but endophyte inoculation had no significant effect on either of these OAs.

Osmotic stress first decreased and then increased the acetate content (Fig. 5D), whereas first increased and then decreased the fumarate content of the E- (Fig. 5G). The acetate content of the E+ was significantly greater than that of E- subjected to 5\% and $10 \%$ PEG. The fumarate content of the E+ was significantly lower than that of Esubjected to 5\% PEG, but it was significantly greater than that of E- subjected to $15 \%$ and $20 \%$ PEG. 

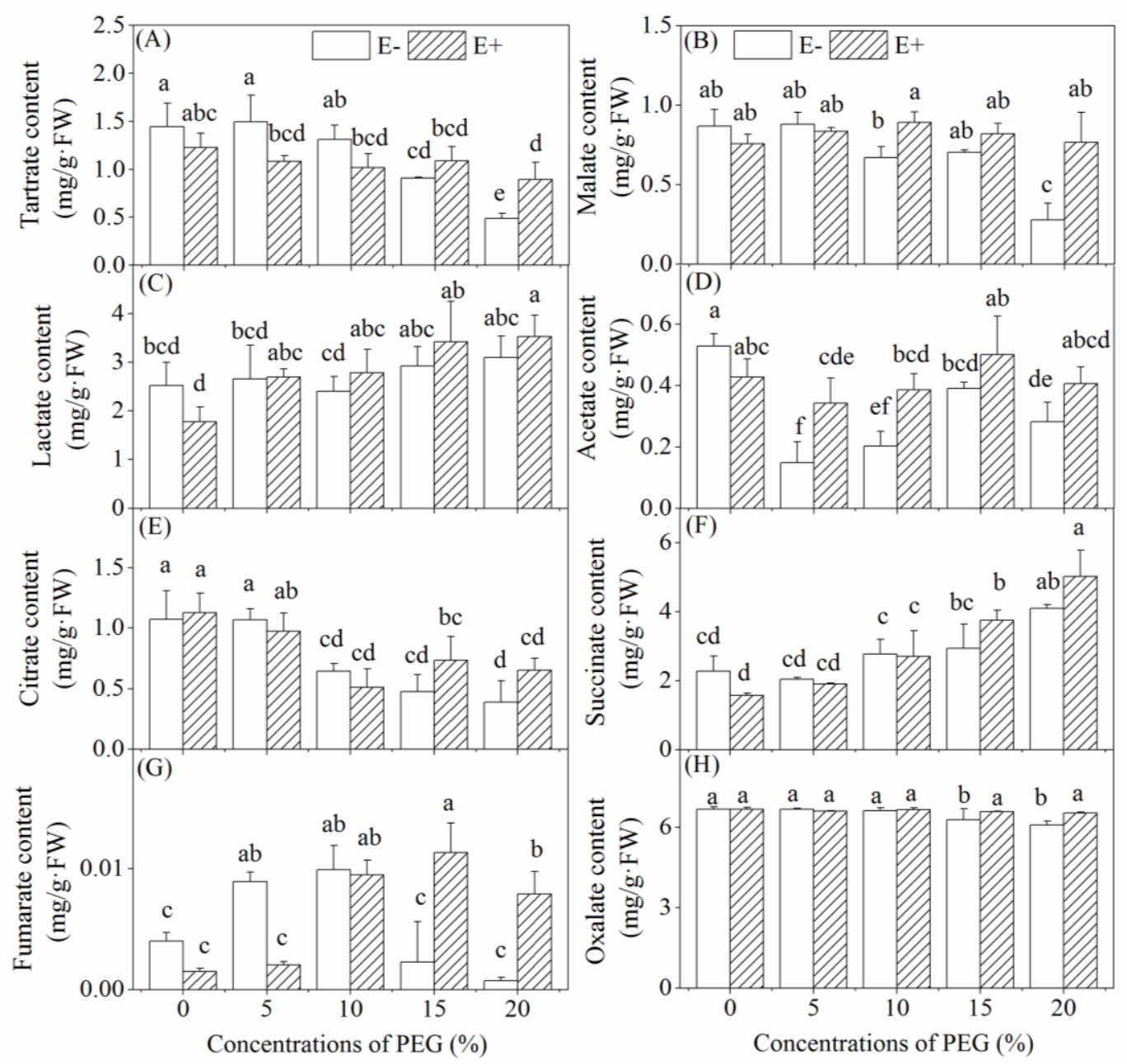

Figure 5. Effects of endophyte inoculation on the accumulation of eight OAs in the roots of rice seedlings subjected to osmotic stress. The bars indicate the standard deviation ( $n=3)$. Different letters indicate a significant difference at $P<0.05$ (LSD test)

\section{Discussion}

It is well established that osmotic stress significantly inhibits growth by plants (Swapna and Shylaraj, 2017; Nahar et al., 2018). We found that osmotic stress produced significant depressive effect on the rice growth (Table 1). PGPR has been shown to increase plant resistance to osmotic stress (Ghosh et al., 2019). Our results suggest that endophyte inoculation alleviated decreases in plant height, the shoot dry weight and Chl content caused by osmotic stress.

Ion-mediated up-regulation of xylem hydraulics plays an important role in optimizing the translocation of water and nutrients, as well as in regulating plant tolerance (Oddo et al., 2011). The water potential in soil significantly affected the uptake of mineral nutrients (Salehi et al., 2016). Drought stress prevents the absorption of mineral nutrients by tomato (Sánchez-Rodríguez et al., 2010). Salt stress decreased Ca, Mg, Fe, and Zn concentrations in lucerne and white melilot (Yasar et al., 2014). In this research, we found that osmotic stress significantly decreased the uptake of $\mathrm{K}$ and Fe by the leaves, as well as the uptake of $\mathrm{Ca}, \mathrm{Mg}$, and P by the roots. Sucre and Suárez (2011) suggest that plants increase 
absorption of $\mathrm{Na}^{+}$when they are subjected to water stress. Similar to their results, we noted that the $\mathrm{Na}$ content of rice seedlings was significantly increased under lowconcentration PEG. The content of microelement $\mathrm{Ni}$ in rice seedlings was significantly increased by osmotic stress, which could lead to toxicity.

Endophytes can improve the uptake of many mineral nutrients in plants (Song et al., 2014). Reestablishing the ionic homeostasis of plants under osmotic stress can increase plant resistance, which can decrease the severity of injuries caused by water deficits and alleviate growth inhibition (Waraich et al., 2011). We observed that endophyte inculation enhanced accumulation of most mineral nutrients which alleviated the detrimental effect of osmotic stress on rice seedlings (Table 2). Increased abundance of mineral nutrients, particularly $\mathrm{K}, \mathrm{Ca}, \mathrm{Mg}$ and $\mathrm{P}$, can improve the cell water potential, stomatal conductance, Chl content and photosynthetic rate of plants (Ruiz-Sánchez et al., 2010). Furthermore, endophyte inculation inhibited accumulation of Ni under osmotic stress, which may have alleviated the toxic effect of excessive $\mathrm{Ni}$ on the E+.

OAs play a vital role in protecting plants from stress by regulating osmotic potential, ionic balance, and other cellular processes (Ma et al., 2011). Accumulation of OAs is an important process involved in the development of increased drought tolerance (Jespersen et al., 2017; Kang et al., 2019). In Phyllanthus, drought stress increased the abundance of OAs such as malic, succinic, and citric acids (Filho et al., 2018). Moreover, the increased abundance of OA, such as malate, citrate and oxalate, can improve drought tolerance of ipt transgenic creeping bentgrass (Merewitz et al., 2012). In this study, the lactate and succinate contents of rice increased as osmotic stress increased. However, Dickinson et al. (2018) found that legumes suffering from abiotic stress showed decreased abundance of many OAs, including malate and citrate. We also found that the tartrate, malate and citrate contents of rice decreased as osmotic stress increased. Griesser et al. (2015) reported increased abundance of citrate, succinate and tartarate in rapevine leaves under drought stress, while that of malate was decreased. These results suggest that different OAs change in different manners in response to stress.

Endophytes can modulate OA metabolism in plants (Singh et al., 2018). Wu et al. (2018) showed that the accumulation of OAs (oxalate, malate and citrate) in the rhizosphere of Brassica napus was improved by endophytic fungus Piriformospora indica. The tolerance of Nicotiana benthamiana to water stress was enhanced due to increased accumulation of some OAs as a result of the presence of fungal endophytes (Dastogeer et al., 2017). In this study, endophyte inoculation significantly enhanced the accumulation of fumarate in the leaves of rice seedlings, and the accumulation of malate, oxalate, fumarate in the roots, which indicated that the leaves and roots trigger different changes in OA metabolism to increase tolerance to water stress.

\section{Conclusions}

Osmotic stress altered the accumulation of OAs and inhibited the uptake of nutrient element by rice seedlings, which alter plant growth and stress tolerance. The endophyte used in the present study is capable of enhancing accumulation of some OAs and improving nutrient absorption. The increased content of OAs and nutrient elements in E+ promoted rice growth, facilitated osmotic adjustment, and induced osmotic stress tolerance. These findings suggest that endophytes could be used to improve plant resistance to abiotic stress in an eco-friendly way. There are intricate interactions between 
plant metabolism changes and each stress, so future study will investigate the signaling pathways involved in the activation of these metabolism changes.

Acknowledgements. This study was financially supported by grants from the National Natural Science Foundation of China (31470398, 31600314, and 31270369) and the Department of Education of Liaoning Province (LZD202004, LZD201901 and LJC201912). We thank SCINET for linguistic assistance during the preparation of this manuscript.

\section{REFERENCES}

[1] Ashraf, M., Harris, P. J. C. (2004): Potential biochemical indicators of salinity tolerance in plants. - Plant Science 166: 3-16.

[2] Ashrafi, M., Azimi-Moqadam, M. R., Moradi, P., MohseniFard, E., Shekari, F., KompanyZareh, M. (2018): Effect of drought stress on metabolite adjustments in drought tolerant and sensitive thyme. - Plant Physiology and Biochemistry 132: 391-399.

[3] Barnaby, J. Y., Fleisher, D., Reddy, V., Sicher, R. (2015): Combined effects of $\mathrm{CO}_{2}$ enrichment, diurnal light levels and water stress on foliar metabolites of potato plants grown in naturally sunlit controlled environment chambers. - Physiologia Plantarum 153: 243-252.

[4] Bhatt, R. M., Selvakumar, G., Upreti, K. K., Boregowda, P. C. (2015): Effect of biopriming with enterobacter strains on seed germination and seedling growth of tomato (Solanum lycopersicum L.) under osmotic stress. - Proceedings of the National Academy of Sciences, India Section B: Biological Sciences 85: 63-69.

[5] Bowne, J. B., Erwin, T. A., Juttner, J., Schnurbusch, T., Langridge, P., Bacic, A., Roessner, U. (2012): Drought responses of leaf tissues from wheat cultivars of differing drought tolerance at the metabolite level. - Molecular Plant 5: 418-429.

[6] Chinnaswamy, A., Coba de la Peña, T., Stoll, A., de la Peña Rojo, D., Bravo, J., Rincón, A., Lucas, M. M., Pueyo, J. J. (2018): A nodule endophytic Bacillus megaterium strain isolated from Medicago polymorpha enhances growth, promotes nodulation by Ensifer medicae and alleviates salt stress in alfalfa plants. - Annals of Appiled Biology 172: 295308.

[7] Dastogeer, K. M. G., Li, H., Sivasithamparam, K., Jones, M. G. K., Du, X., Ren, Y. L., Wylie, S. J. (2017): Metabolic responses of endophytic Nicotiana benthamiana plants experiencing water stress. - Environmental and Experimental Botany 143: 59-71.

[8] Devnarain, N., Crampton, B. G., Chikwamba, R., Becker, J. V. W., O'Kennedy, M. M. (2016): Physiological responses of selected African sorghum landraces to progressive water stress and re-watering. - South African Journal of Botany 103: 61-9.

[9] Dickinson, E., Rusilowicz, M. J., Dickinson, M., Charlton, A. J., Bechtold, U., Mullineaux, P. M., Wilson, J. (2018): Integrating transcriptomic techniques and k-means clustering in metabolomics to identify markers of abiotic and biotic stress in Medicago truncatula. Metabolomics 14: 126.

[10] Filek, M., Walas, S., Mrowiec, H., Rudolphy-Skorska, E., Sieprawska, A., BiesagaKoscielniak, J. (2012): Membrane permeability and micro- and macroelement accumulation in spring wheat cultivars during the short-term effect of salinity and PEGinduced water stress. - Acta Physiologiae Plantarum 34: 985-995.

[11] Filho, E. G. A., Braga, L. N., Silva, L. M. A., Miranda, F. R., Silva, E. O., Canuto, K. M., Miranda, M. R., de Brito, E. S., Zocolo, G. J. (2018): Physiological changes for drought resistance in different species of Phyllanthus. - Scientific Reports 8: 15141.

[12] Ghosh, D., Gupta, A., Mohapatra, S. (2019): Comparative analysis of exopolysaccharide and phytohormone secretions by four drought-tolerant rhizobacterial strains and their 
impact on osmotic-stress mitigation in Arabidopsis thaliana. - World Journal of Microbiology and Biotechnology 35: 90.

[13] Griesser, M., Weingart, G., Schoedl-Hummel, K., Neumann, N., Becker, M., Varmuza, K., Liebner, F., Schuhmacher, R., Forneck, A. (2015): Severe drought stress is affecting selected primary metabolites, polyphenols, and volatile metabolites in grapevine leaves (Vitis vinifera $\mathrm{cv}$. Pinot noir). - Plant Physiology and Biochemistry 88: 17-26.

[14] Jespersen, D., Yu, J., Huang, B. (2017): Metabolic effects of acibenzolar-s-methyl for improving heat or drought stress in creeping bentgrass. - Frontiers in Plant Science 8: 1224.

[15] Jung, S. C., Martinez-Medina, A., Lopez-Raez, J. A., Pozo, M. J. (2012): Mycorrhizainduced resistance and priming of plant defenses. - Journal of Chemical Ecology 38: 651664.

[16] Kang, Z., Babar, M. A., Khan, N., Guo, J., Khan, J., Islam, S., Shrestha, S., Shahi, D. (2019): Comparative metabolomic profiling in the roots and leaves in contrasting genotypes reveals complex mechanisms involved in post-anthesis drought tolerance in wheat. - Plos One 14: $\mathrm{e} 0213502$.

[17] Kim, J. M., To, T. K., Matsui, A., Tanoi, K., Kobayashi, N. I., Matsuda, F., Habu, Y., Ogawa, D., Sakamoto, T., Matsunaga, S., Bashir, K., Rasheed, S., Ando, M., Takeda, H., Kawaura, K., Kusano, M., Fukushima, A., Endo, T. A., Kuromori, T., Ishida, J., Morosawa, T., Tanaka, M., Torii, C., Takebayashi, Y., Sakakibara, H., Ogihara, Y., Saito, K., Shinozaki, K., Devoto, A., Seki, M. (2017): Acetate-mediated novel survival strategy against drought in plants. - Nature Plants 3: 17097.

[18] Kitir, N., Gunes, A., Turan, M., Yildirim, E., Topcuoglu, B., Turker, M., Ozlu, E., Karaman, M. R., Firlldak, G. (2019): Bio-boron fertilizer applications affect amino acid and organic acid content and physiological properties of strawberry plant. - Erwerbs-Obstbau 61: 129137.

[19] Li, X., Ma, L., Bu, N., Li, Y., Zhang, L. (2017): Endophytic infection modifies organic acid and mineral element accumulation by rice under $\mathrm{Na}_{2} \mathrm{CO}_{3}$ stress. - Plant and Soil 420 : $1-11$.

[20] Li, X., Ma, L., Wang, L., Li, Y., Zhang, L. (2019): Endophyte infection enhances accumulation of organic acids and minerals in rice under $\mathrm{Pb}^{2+}$ stress conditions. Ecotoxicology and Environmental Safety 174: 255-262.

[21] Liang, B., Ma, C., Zhang, Z., Wei, Z., Gao, T., Zhao, Q., Ma, F., Li, C. (2018): Long-term exogenous application of melatonin improves nutrient uptake fluxes in apple plants under moderate drought stress. - Environmental and Experimental Botany 155: 650-661.

[22] Lichtenthaler, H. K. (1987): Chlorophylls and carotenoids: pigments of photosynthetic biomembranes. - Methods in Enzymology 148: 350-382.

[23] Liu, R. J., Chen, Y. L. (2007): Mycorrhizology. - Science Press, 447p.

[24] Ma, Y., Guo, L., Wang, H., Bai, B., Shi, D. (2011): Accumulation, distribution, and physiological contribution of oxalic acid and other solutes in an alkali-resistant forage plant, Kochia sieversiana, during adaptation to saline and alkaline conditions. - Journal of Plant Nutrition and Soil Science 174: 655-663.

[25] Mahdavian, K., Ghaderian, S. M., Schat, H. (2016): Pb accumulation, Pb tolerance, antioxidants, thiols, and organic acids in metallicolous and non-metallicolous Peganum harmala L. under Pb exposure. - Environmental and Experimental Botany 126: 21-31.

[26] Merewitz, E. B., Du, H. M., Yu, W. J., Liu, Y. M., Gianfagna, T., Huang, B. R. (2012): Elevated cytokinin content in ipt transgenic creeping bentgrass promotes drought tolerance through regulating metabolite accumulation. - Journal of Experimental Botany 63: 13151328.

[27] Nahar, S., Sahoo, L., Tanti, B. (2018): Screening of drought tolerant rice through morphophysiological and biochemical approaches. - Biocatalysis and Agricultural Biotechnology 15: $150-159$. 
[28] Oddo, E., Inzerillo, S., La Bella, F., Grisafifi, F., Salleo, S., Nardini, A. (2011): Short-term effects of potassium fertilization on the hydraulic conductance of Laurus nobilis L. - Tree Physiology 31: 131-138.

[29] Ruiz-Sánchez, M., Aroca, R., Muñoz, Y., Polón, R., Ruiz-Lozano, J. M. (2010): The arbuscular mycorrhizal symbiosis enhances the photosynthetic efficiency and the antioxidative response of rice plants subjected to drought stress. - Journal of Plant Physiology 167: 862-869.

[30] Salehi, A., Tasdighi, H., Gholamhoseini, M. (2016): Evaluation of proline, chlorophyll, soluble sugar content and uptake of nutrients in the German chamomile (Matricaria chamomilla L.) under drought stress and organic fertilizer treatments. - Asian Pacific Journal of Tropical Biomedicine 6: 886-891.

[31] Sánchez-Rodríguez, E., Rubio-Wilhelmi, M. M., Cervilla, L. M., Blasco, B., Rios, J. J., Leyva, R., Romero, L., Ruiz, J. M. (2010): Study of the ionome and uptake fluxes in cherry tomato plants under moderate water stress conditions. - Plant and Soil 335: 339-347.

[32] Sheshbahreh, M. J., Dehnavi, M. M., Salehi, A., Bahreininejad, B. (2019): Effect of irrigation regimes and nitrogen sources on biomass production, water and nitrogen use efficiency and nutrients uptake in coneflower (Echinacea purpurea L.). - Agricultural Water Management 213: 358-367.

[33] Sicher, R. C., Barnaby, J. Y. (2012): Impact of carbon dioxide enrichment on the responses of maize leaf transcripts and metabolites to water stress. - Physiologia Plantarum 144: 238253.

[34] Singh, D., Geat, N., Rajawat, M. V. S., Mahajan, M. M., Prasanna, R., Singh, S., Kaushik, R., Singh, R. N., Kumar, K., Saxena, A. K. (2018): Deciphering the mechanisms of endophyte-mediated biofortification of $\mathrm{Fe}$ and $\mathrm{Zn}$ in wheat. - Journal of Plant Growth Regulation 37: 174-182.

[35] Song, M. L., Chai, Q., Li, X. Z., Yao, X., Li, C. J., Christensen, M. J., Nan, Z. B. (2014): An asexual Epichloë endophyte modifies the nutrient stoichiometry of wild barley (Hordeum brevisubulatum) under salt stress. - Plant and Soil 387: 153-165.

[36] Sucre, B., Suárez, N. (2011): Effect of salinity and PEG-induced water stress on water status, gas exchange, solute accumulation, and leaf growth in Ipomoea pes-caprae. Environmental and Experimental Botany 70: 192-203.

[37] Swapna, S., Shylaraj, K. S. (2017): Screening for osmotic stress responses in rice varieties under drought condition. - Rice Science 24: 253-263.

[38] Timpa, J. D., Burke, J. J., Quisenberry, J. E., Wendt, C. W. (1986): Effects of water stress on the organic acid and carbohydrate compositions of cotton plants. - Plant Physiology 82: 724-728.

[39] Van Oosten, M. J., Stasio, E. D., Cirillo, V., Silletti, S., Ventorino, V., Pepe, O., Raimondi, G., Maggio, A. (2018): Root inoculation with Azotobacter chroococcum 76A enhances tomato plants adaptation to salt stress under low N conditions. - BMC Plant Biology 18: 205.

[40] Waraich, E. A., Saifullah, A. R., Ehsanullah, M. Y. (2011): Role of mineral nutrition in alleviation of drought stress in plants. - Australian Journal of Crop Science 5: 764-777.

[41] Witt, S., Galicia, L., Lisec, J., Cairns, J., Tiessen, A., Araus, J. L., Palacios-Rojas, N., Fernie, A. R. (2012): Metabolic and phenotypic responses of greenhouse-grown maize hybrids to experimentally controlled drought stress. - Molecular Plant 5: 401-417.

[42] Wu, M., Wei, Q., Xu, L., Li, H., Oelmüller, R., Zhang, W. (2018): Piriformospora indica enhances phosphorus absorption by stimulating acid phosphatase activities and organic acid accumulation in Brassica napus. - Plant and Soil 432: 333-344.

[43] Yasar, F., Uzal, Ö., Yasar, Ö., Ellialtioglu, Ş. (2014): Root, stem, and leaf ion accumulation in drought stressed green bean (Phaseolus vulgaris L.) genotypes treated with PEG-6000. - Fresenius Environmental Bulletin 23: 2656-2662. 